\title{
La morale du professeur, Eirick Prairat
}

PuF, Paris, 2013

\section{Jean-Pierre Véran}

\section{CpenEdition}

\section{Journals}

Édition électronique

URL : http://journals.openedition.org/ries/3674

DOI : $10.4000 /$ ries.3674

ISSN : 2261-4265

Éditeur

Centre international d'études pédagogiques

Édition imprimée

Date de publication : 15 avril 2014

Pagination : 33-34

ISBN : 978-2-85420-603-6

ISSN : $1254-4590$

\section{Référence électronique}

Jean-Pierre Véran, "La morale du professeur, Eirick Prairat », Revue internationale d'éducation de Sèvres [En ligne], 65 | avril 2014, mis en ligne le 15 avril 2014, consulté le 22 septembre 2020. URL : http:// journals.openedition.org/ries/3674 ; DOI : https://doi.org/10.4000/ries.3674

Ce document a été généré automatiquement le 22 septembre 2020

(c) Tous droits réservés 


\section{La morale du professeur, Eirick Prairat}

PuF, Paris, 2013

Jean-Pierre Véran

\section{RÉFÉRENCE}

La morale du professeur, Eirick Prairat, PuF, Paris, 2013, 288 p.

1 On ne peut sans doute parler de la morale du professeur sans la référer à un contexte ni à un modèle politique d'éducation. Selon que ce modèle repose sur la transmission magistrale ou sur l'expérimentation, sur une autorité institutionnelle ou fonctionnelle du maître, le modèle professoral diffère et cela a sans aucun doute un impact sur la morale du professeur. Il reste que la réflexion sur la morale du professeur exerçant dans un contexte donné permet un questionnement utile sur la déontologie et l'éthique professionnelle enseignante.

2 Dans cet ouvrage, Eirick Prairat, professeur en sciences de l'éducation à l'Université de Lorraine, inscrit son propos dans le contexte français, mais sa réflexion sur les fondements d'une morale enseignante repose sur une approche philosophique de l'enseignement plus générale et se réfère à des codes et chartes déontologiques établis en Belgique, au Canada (Ontario) ou en Suisse romande.

3 À la différence, par exemple, de l'arrêté du $1 / 7 / 2013^{1}$ qui définit le référentiel des compétences des métiers du professorat et de l'éducation ou des textes qui l'ont précédé, ce travail ne cherche pas à établir le portrait du professeur idéal mais questionne, à partir même de la pratique professionnelle, les enjeux moraux, les questions éthiques que doit affronter le professionnel de l'enseignement et de l'éducation.

4 Si, de la circulaire de Jules Ferry appelée Lettre à M. l'instituteur, du 27 novembre 1883, à l'arrêté de 2013, en passant par la loi portant statut, droits et obligations des fonctionnaires de 1983, les textes réglementaires ne manquent pas sur le sujet, Eirick Prairat contribue à éclairer les questions qu'ils posent plus qu'ils ne les résolvent. 
5 À quelle conception normative faut-il se référer explicitement? Entre " déontologisme ", " conséquentialisme » et "vertuisme ", il faut choisir si l'on veut clairement fonder une morale enseignante partagée. On n'aura pas, en effet, le même point de vue moral selon que l'on considère que certains actes sont a priori moraux ou immoraux ou que la moralité d'un acte ne se mesure qu'à ses conséquences ou même que, au-delà des actes, c'est l'étoffe moral de l'agent qu'il faut jauger.

6 Eirick Prairat ne propose pas un choix exclusif mais, en examinant chacune de ces options, il en retient des éléments qui vont contribuer à la définition d'un déontologisme tempéré. Par exemple, réfléchissant aux vertus professionnelles des enseignants, il en retient trois : le tact, le sens de la justice et la sollicitude.

7 Mais l'ouvrage apporte dans sa dernière partie des directions de travail précieuses en ce qui concerne la formation des enseignants. Il ne s'agit évidemment ni de leur inculquer un catéchisme ni de leur apporter des réponses toutes faites aux questions morales posées lors de leur exercice professionnel. Eirick Prairat propose que cette formation repose sur trois piliers : celui des notions fondamentales (le légal, le moral, l'impartialité, la question des devoirs...), celui des exemples de codes ou chartes déontologiques pour les enseignants de divers pays, et celui, essentiel à nos yeux, des dilemmes et expériences de pensées. C'est en effet par une réflexion argumentée sur des situations professionnelles concrètes que peut se construire une interaction pertinente entre singularité du contexte et généralité de la règle. Et cette délibération a lieu au sein d'un groupe de pairs, où chacun se sent responsable à l'égard de chacun.

Eirick Prairat se livre, en 2013, à la relecture critique de sa proposition de déontologie enseignante publiée en $2009^{2}$. S'il en conserve les principes (éducabilité, autorité, respect, responsabilité), il éprouve le besoin de préciser le bien-fondé de chaque article et de certaines sources normatives, d'alléger certains articles ou d'en livrer quelques commentaires explicatifs. On peut regretter que n'ait pas été revue la formulation pour le moins ambiguë de l'article VI : l'enseignant «cite les références des textes et documents qu'il utilise. Le savoir s'adosse toujours à des sources vérifiées et vérifiables. Un enseignant n'est pas un journaliste. »Ces préoccupations déontologiques, les journalistes les font explicitement leurs depuis bien longtemps. C'est justement parce que cette norme déontologique est partagée entre les deux professions que la formulation de cet article mériterait d'être amendée.

\section{NOTES}

1. http://www.education.gouv.fr/pid25535/bulletin_officiel.html?cid_bo=73066/

2. Prairat, Eirick, De la déontologie enseignante, PuF, 2009. 


\section{AUTEURS}

\section{JEAN-PIERRE VÉRAN}

Inspecteur d'académie honoraire, formateur associé à l'Université Montpellier 2 où il enseigne notamment les politiques éducatives et la gouvernance des organisations scolaires. Membre du comité de rédaction de la Revue internationale d'éducation de Sèvres, il est co-auteur de : Le Conseiller principal d'éducation : de la vie scolaire à la politique éducative (2e édition, 2012); De l'emploi du temps aux emplois des temps : pour une approche globale du temps scolaire (2011), Berger-Levrault. 